\title{
How does household characteristics influence their waste management?
}

\author{
Dwini Handayani ${ }^{1, *}$, Beta Yulianita Gitaharie ${ }^{1}$, Restananda Nabilla Yussac ${ }^{1}$, and Rian \\ Sabrina Rahmani ${ }^{1}$ \\ ${ }^{1}$ Faculty of Economics and Business, Universitas Indonesia
}

\begin{abstract}
The amount of waste generated is ever-increasing due to population growth, however adequate waste management has never been a focus in everyday life. The action of the household as the beginning stage of waste management is also crucial. How households manage their waste is also influenced by their socio-economic characteristics. This study aims to investigate household characteristics that influence their waste management. This study employed the Indonesian Family Life Survey 2014 data using probit regression method. The result shows that location significantly affect waste management behaviour which households in urban areas hold higher probability to manage their waste compared to those in rural areas. The level of education and knowledge also have positive impact on household's waste management. The level of income also positively affect waste management behaviour of households. Demographic variables such as age and gender are significant and indicate that women and older people have better waste management compared to men and younger people. These results support the hypothesis that household's waste management behaviour is significantly influenced by their characteristics.
\end{abstract}

\section{Introduction}

Indonesia is now considered as one of the most rapidly urbanizing countries in the world which almost $56 \%$ of the Indonesian population lives in urban area [1]. Similar to the majority of other countries, the process of urbanization has occurred in tandem with economic development which changes the level of social welfare. Thus, it in turn affects the pattern of consumption that leads to the increase of waste produced by the community [2] .

In 2016, it was estimated that approximately 85,000 tons of solid waste is generated in Indonesia and by 2025 , this amount is expected to increase to 150,000 tons [3]. However, solid waste management in Indonesia is still inadequate, collection rate is low and still not disposed in sanitary landfill with appropriate environmental and social standards [3]. Waste is only transported and placed in the final disposal without any further treatment [2]. These problems create bad publicity that contribute to environmental degradation.

\footnotetext{
*Corresponding author: dwiniarianto@yahoo.com
} 
According to [4], household plays a crucial role in ensuring proper waste disposal. In addition, [6] identified that socio-demographic factors such as education, income level, household size and gender influence household's environmental behaviour. While [7] noticed that environmental awareness, purchasing behaviour, religion and personality traits are main factors that contribute to household's waste management.

However, there is still a lack of empirical study to investigate how household's socioeconomic characteristics determine environmental behaviour especially in Indonesia's case. This study aims to investigate further the influence of socio-economic characteristics on waste management in Indonesia A better understanding on how to influence people to adopt pro-environmental behaviour has been identified as an important key to address environmental challenges that we currently face [5]. These determinants also vary widely depend on their context, therefore further research is still required [8].

\section{Literature review}

Scholars have noticed that knowledge and perception of households in waste management is likely to influence the success of any waste management [4] . Waste management through the 3Rs - reduce, reuse, and recycle - has been addressed as priority to meet the sustainable development goals (SDGs), particularly Goal 12 (Target 12.5) The 3Rs action can start from homes.

A study by [10] using data at household level in Indonesia shows that knowledge of waste management is an important factor in household solid waste separation. [11] argued that household knowledge in which defined as the degree to which households have the necessary information to make utility-maximizing decisions about the handling of their waste, has positive effect on the amount of household hazardous waste collected and recycled. In addition, they also found that differences in income and demographic factors also influence the collection and recycling behaviour of the households.

Education is widely believed as important factor to shape pro-environmental behaviour of households. Study of [6] empirically showed that higher education has positive impact on the recycling rate. [13] used the theory of planned behaviour to show that the intention separate collection towards household solid waste are significantly influenced by the behaviours of others, facility conditions, and moral obligations. [10] also identified factors that affect household waste separation, these factors include environmental concern, waste management counselling, surface area, homeownership, income, building type and education.

Social and moral norms are other significant factors that influence household's waste management behaviour. [14] argued that in the early stage of recycling system, social norms were found to be important for source sorting however it is not important in the mature recycling system. Hence, they suggested that policy maker should focus on moral norms when the infrastructure in waste management schemes are still underdeveloped. In addition, waste collection system and waste management infrastructure are also considered as critical factors that affect household waste management behaviour [6]. In accordance with this argument, [14] also argued that the convenience factors in waste management schemes such as the simplicity in waste collection and waste management facility become important motivators for household to recycle.

\section{Method}

In this paper, the household characteristics are represented by the head of the household characteristics. The head of the household is responsible to set the household boundaries 
and rules such as everyday activity as well as the method to manage their household waste. This study used the fifth wave of the Indonesian Family Life Survey conducted in 2014 in 13 provinces in Indonesia. The sample in IFLS represents 83 percent of the Indonesian household. The total sample used in the model is 15,904 households.

The dependent variable used in the model is response variable of how household manage their waste. Therefore, this study employed probit regression method. Households are categorised as managing their waste when they use some modern waste disposal or has a community waste disposal system. On the contrary, households are considered as not managing their waste when they only burn and throw away either to the river, sewer, ocean, or unattended field without any further disposal system. The equation to be estimated is shown as follows:

$$
\begin{aligned}
& \text { Waste }_{i}=\beta_{0}+\beta_{1} \text { Urban }_{i}+\beta_{1} \text { Sex }_{i}+\beta_{2} \text { Age }_{i}+\beta_{3} \text { LowEduc }_{i} \\
& +\beta_{4} \text { MidEduc }_{i}+\beta_{5} \text { InExpend }_{i}+\beta_{6} \text { Knowledge }_{i}+\beta_{7} \text { Partcp }_{i}+\varepsilon
\end{aligned}
$$

Where:

Waste $\quad=1$, when the household uses any waste management method,

$=0$, if otherwise

Urban $\quad=1$, if the household lives in urban areas,

$=0$, if in rural

Sex $\quad=1$, if the head of the household is a man

$=0$, if otherwise

Age $\quad=$ Age of the household head

Loweduc $=1$, If the household head has low education

Mideduc $\quad=1$, If the household head has middle education

lnExpend = household expenditure in nature log form

Knowledge $=1$, if household has knowledge on waste program conducted in their community

$=0$, if otherwise

Participation $=1$, if household participates in their community waste management activities $=0$, if otherwise

$\varepsilon \quad=$ Error term

\section{Result and discussion}

The estimation result is shown on Table 1 . The inferential shows that all variables chosen in the model significantly influence the household waste disposal behaviour.

Table 1. Analysis of household waste management using probit model.

\begin{tabular}{cc} 
Dependent : & Marginal effects \\
Household waste management & \\
\hline (1- if households use any waste management, 0- otherwise) & $.4120401^{* * *}$ \\
Urban & $(.00796)$ \\
LnExpend & $.0856311^{* * *}$ \\
LowEduc & $(.00629)$ \\
MidEduc & $-.1502578^{* * *}$ \\
Knowledge & $(.01269)$ \\
\end{tabular}




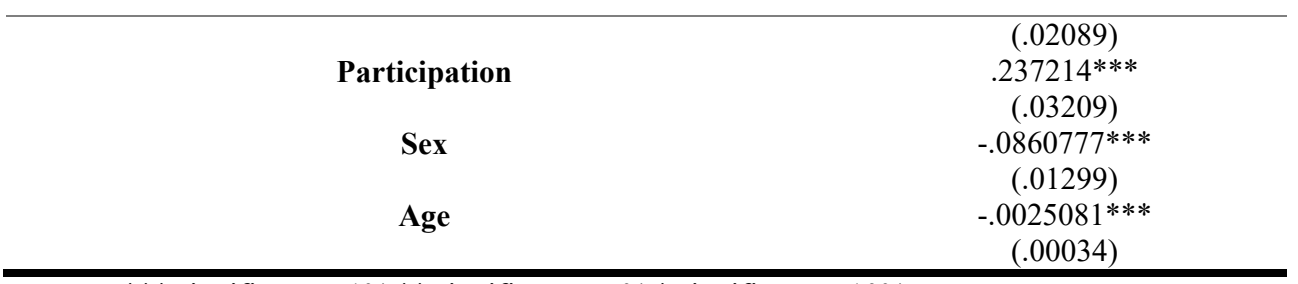

Notes : ${ }^{* * *}$ significant at $1 \%,{ }^{* *}$ significant at $5 \%,{ }^{*}$ significant at $10 \%$

Number in parentheses shows standard errors

It can be seen from Table 1 above that the probability of household to manage their household $(\mathrm{HH})$ waste is 0.41 percentage points higher for those living in urban areas compared to households living in rural areas. It is possibly unsurprising since urban areas are tend to be more modern in terms of infrastructure and those areal so more equipped with modern amenities needed to provide better treatment for their waste. A study by [15] shows that community-based solid management, run in 7 cities in Indonesia, has been successfully reduced waste volume up to $80 \%$. While people in rural areas in Indonesia generally still use traditional methods such as bury, burn or just throw them into the river. Uncontrolled traditional waste disposal may be hazardous to the environment - flood, dirty and unpleasant smelled environment; as well as hazardous to health-skin issues, abdominal deseases, and other health complication. One way to manage household waste is to separate wet wastes, which are mainly organic that come from food waste, from dry ones. Organic wastes, if managed properly, can be converted into compost which can be used as fertilizer to plants. Organic fertilizers are safer to use than chemical ones. Another option is to make what is called "biopori" holes - cynlindrical holes digged into the soil and are filled with properly separated and clean/washed wet wastes. The biopori holes absorb more water in the case of heavy rainy season, hence, help to reduce potential flood caused by waste-plugged water flow. This result supports the study from [15] which showed that location significantly affect waste management behaviour in which urban communities have better waste management behaviour than those in rural areas.

Furthermore, the estimated results also empirically show that household sociodemography characteristics have important role to determine waste management. The level of education is directly proportional to household waste management. [9] argued that education is crucial to the effectiveness of waste management strategy and it potentially influences a large number of people both in short and long term. Education will increase the people's awareness and understanding of the importance of waste management. This can be prepared from early stage education and be maintained by applying it in the daily life. Previous studies by [6] also supported the result that better education level has positive impact on pro-environmental behaviour. The result also is supported by the previous findings from [10] which showed that knowledge is important to influence household to separate their waste.

Women and older people have higher probability to manage their waste compared to men and younger generation. It may be due to women tend to care more on cleanliness, health, and are more enthusiastic to do waste sorting. Waste sorting is the simplest practice of household waste management and it can be done manually. Waste is generally sorted based on the elements: paper/cardboard, glass, plastics, metals, and others. A study by [17] explained that women tend to be more involved in recycling tasks since they traditionally have greater role in domestic tasks. Out of these sorted unorganic wastes, women recycle and creatively turn the used materials into handicrafts, bags, and others. Some are made for owned use and some are for sale. Such practices support to ensure sustainable consumption and production patterns as aimed by Goal 12 of SDGs. The higher the age then the probability of their engagement in the community's activity is also higher. Their 
participation and involvement in the community will increase the awareness of waste management. This result confirms the argument from a researcher that middle aged and older people are more likely to be more involved in recycle and waste management program [17].

\section{Conclusion}

This study provides an insight to investigate the role of household characteristics in determining waste management in the household level. The result empirically shows that household characteristics significantly affect their waste management behaviour. Education and knowledge play an important role since the educational levels can crucially affect the success of waste management awareness programmes [16]. The result also underlines that spatial disparities exist in waste management between rural and urban areas. Income also seems to be important in influencing waste management behaviour since people with higher income are presented with higher affordability, higher living standards and consequently contribute to increase of the generated amount of waste.

However, this study recommends further and more comprehensive research to gain better understanding on how household characteristics affect their waste management behaviour. Better household waste management, higher participation and involvement of the people in environmental community activities will contribute to the achievement of Indonesia toward the SDGs.

\section{References}

1. World Bank, Indonesia's Urban Story (2016)

2. A. Anjani, Master Thesis Household Waste Management in Indonesia (2011)

3. World Bank, SOLID WASTE (2016)

4. T.T. Kwailane, T.D. Gwebu, and W.L. Hambira, African Geogr. Rev. 35, 2, 117-133 (2016)

5. T. Tadesse, A. Ruijs, F. Hagos, Waste Manag. 28 (2008)

6. B.G. Mwanza, C. Mbohwa, and A. Telukdarie, Procedia Manuf. 21, 615-622 (2018)

7. R. Diaz-Ruiz, Costa-Font, J.M., Gil, Are households feeding habits and waste management practices determinant in order to swing over food waste behaviours? The case of Barcelona Metropolitan Area (2015)

8. F. Corsini, N. M. Gusmerotti, F. Testa, and F. Iraldo, Waste Manag. 79, 132-141 (2018)

9. M. Purcell, W. L. Magette, Waste Manag. 30, 10, 1997-2006 (2010)

10. Zakianis, Sabarina, I.M. Djaja, Int. J. Waste Resour. 07, 04 (2017)

11. K. Lim-Wavde, R.J. Kauffman, G.S. Dawson, MATEC Web Conf. 68, 14003 (2016)

12. S.F. Sidique, S.V. Joshi, F. Lupi, Resour. Conserv. Recycl. 54, 4, 242-249 (2010)

13. Z. Wang, X. Dong, and J. Yin, J. Clean. Prod. (2016)

14. J. Miliute-Plepiene, O. Hage, A. Plepys, A. Reipas, Resour. Conserv. Recycl. 113, 40 $52(2016)$

15. F. Fladerer, S. Wahyudi, H.H. Al- Rasyid, Y. Ismawati, M. Riese, Decentralized Urban Solid Waste Management in Indonesia (2009)

16. S. Ciuta, T. Apostol, V. Rusu, Sustain. 7, 1, 916-931 (2015)

17. S.F. Sidique, F. Lupi, S. V. Joshi, Resour. Conserv. Recycl. 54, 3, 163-170 (2010)

18. S. Boateng, P. Amoako, D.O. Appiah, A.A. Poku, E.K. Garsonu, J. Environ. Public Heal., 1-10 (2016) 